\title{
Familial isolated clinodactyly of fingers
}

INSERM

\section{Source}

INSERM. (1999). Orphanet: an online rare disease and orphan drug data base. Familial isolated clinodactyly of fingers. ORPHA:295014

Familial isolated clinodactyly of fingers is a rare, genetic, non-syndromic, congenital limb malformation disorder characterized by angulation of a digit in the radio-ulnar (coronal) plane, away from the axis of joint flexion-extension, in several members of a single family with no other associated manifestations. Deviation is usually bilateral and commonly involves the fifth finger. Affected digits present trapezoidal or delta-shaped phalanges on imaging. 